\title{
Research on the Strategy of Integrating Civilian Consciousness into TV News Work
}

\author{
Kezhen Li
}

Dalian Art College, Liaoning, Dalian, 116600

\author{
Keywords: New Media Era; Civilian Awareness; Television News Work
}

\begin{abstract}
The civilian consciousness reflects the spiritual core of "people-oriented" spirit. The integration of TV news work into civilian consciousness can greatly enhance the depth and breadth of TV news, so that it advances with the times, integrates with modern media, deepens the audience, and improves the media. The effective strategy of integrating civilian consciousness into TV news work should be based on the specific work links of TV news and infiltrate from various aspects such as content and form.
\end{abstract}

\section{Introduction}

The consciousness of the common people, which has existed in ancient times, is one of the concrete manifestations of the humanistic spirit. It is reflected in the work of TV news and is a deep concern and exploration of people's livelihood. Since the 21st century, digital information has developed rapidly. Digital TV and various types of media terminals have gradually occupied a dominant position in the media industry. The emergence of new media, the continuous integration of new and old media, has made the trend of popularization of news communication more obvious. Actively integrating the awareness of civilians in TV news work will more accurately reflect life and tap into the deep people's livelihood issues. The integration of civilian consciousness into TV news work can be carried out in several aspects, such as the content of the news program, the perspective of the cut-off, the narrative language, etc., and combined with modern means to realize the civilian presentation of TV news from "form” to "god", thus expanding its Influence.

\section{The Consciousness of the Common People and Its Specific Significance in the Work of Television News}

The consciousness of the common people comes from the "people". In ancient China, there was a simple "people-oriented" thought. "The country is based on the people, the people are eating for the sky." The "people" here refers to the people, which is different from the nobility and the privileged class. . Therefore, "civilian consciousness is the product of society and the origin of human nature." Tracing back to the roots, the civilian consciousness reflects the concern of "people", cares about the value of people, people, and the existence of human beings. It contains the core of humanistic spirit and humanistic care. The "people-oriented" of humanistic spirit and humanistic care reflects the idea that everyone is equal, that is, the rights and interests of different people should be protected and respected together, and people should be exchanged on an equal footing. Correct. However, in the actual application process, the common sense of the civilians is reflected by different people facing different objects, so the civilian consciousness is different in different fields. For example, in schools, the awareness of civilians is reflected in the "life" of education and teaching; in the field of journalism, it is "centered on the audience".

In the traditional TV news work, TV news is in a "high" position, often playing the role of political propaganda. With the development of social and TV journalism, this "official mouthpiece" type of news propaganda is gradually not an audience. Accepted, and the "people's livelihood ideology" led by the state and the government also made the TV news work face in-depth reform, so the civilian consciousness gradually turned into "the journalism practitioners abandoned the superiority brought about by professional and technological advantages, changed the condescending 
and looked down upon everything."In the 21st century, information technology has developed rapidly, and the "network" has been deeply integrated into people's lives. New media has emerged in an endless stream. The news media and carriers have been rapidly updated, and the way of news dissemination has undergone tremendous changes. In this context, the re-integration and optimization of broadcasting, television and Internet has become a new development trend and direction. Various media forms are intertwined and mutually utilized, so that their respective communication functions, advantages and values are fully utilized. At the same time, the public's attention to themselves, the active participation of TV news has greatly improved, the audience is no longer a passive "recipient" of TV news, but also an active "screener", not close to reality, not close to the people TV news of life will no longer be of concern. Based on this, the civilian consciousness of TV news work is further deepened. It is necessary not only to communicate more closely with the audience, but also to deepen the audience's heart, pay attention to the life and emotions of ordinary people, and treat the people's livelihood and the people's livelihood with a more "popularized" attitude. .

\section{The Current Problems in TV News Work}

The development of social economy and science and technology has allowed China to gradually enter the era of civilians. The people's ideological concepts have undergone profound changes, paying more attention to life and self-care, and have more rational judgments on information transmission. In such an era, TV journalists, in order to better achieve the mission of the media, actively reflect the spirit of the times, and express the voices and demands of the people, must inevitably implement the "civilian consciousness" and let the civilian consciousness take root in the heart. Sprouting, learning to observe life from the perspective of civilians, thinking about reality, the only way to meet the general psychology of today's audience, to achieve the "communication of the mind" with the audience, thereby resonating and achieving the purpose of communication. However, at present, there are still many problems in the process of infiltrating the consciousness of civilians in TV news programs, which can be divided into the following two points:

There is a homogenization phenomenon and there is a tendency to entertain. In order to reflect their own civilian consciousness, TV news programs have gradually turned to pay more attention to people's livelihood and people's feelings. However, the content structure and narrative methods of many people's livelihood news are similar, seemingly concerned about "people's life", but the same content often causes The aesthetic fatigue of the audience is difficult to achieve the desired results. In order to gain more attention and ratings, some TV news programs tend to pay more attention to the topicality and the irritability of the images when selecting and editing the content, and draw attention through the "manufacturing gimmicks" method for specific types. The over-rendering of the people's livelihood issue has gained the corresponding attention and became a hot topic for the public after a meal. However, because it often exaggerates some facts, it is out of the essence of the pursuit of authenticity and objectivity, and tends to be entertaining, so it cannot be practical. Reflecting real life and providing bad guidance to the public has greatly reduced the quality of TV news.

The news content is superficial and lacks in-depth mining. The TV news work under the guidance of "civilian consciousness" should pay attention to the people's real life and vital interests. However, although the current TV news program is trying to start from the ordinary mentality of the people, it still lacks the value of civilians to examine the problem. Some livelihood TV news simply presents local customs, social phenomena, lack of exploration of social causes and background factors of events, and some livelihood TV news. Excessively emphasizing the livelihood of the people's lives does not effectively express the true emotional appeals of the people. Interviews, materials, videography, etc., as well as later editing and production, are subject to representational problems. It is difficult for the audience to obtain more valuable information from them. This will also result in the loss of the audience. 


\section{The Effective Strategy of Integrating Civilian Consciousness into TV News Work}

Effectively integrate the awareness of civilians in TV news work, and improve the effectiveness and achievements of TV news work with the help of civilian consciousness. We can try to make efforts from TV news topic selection, narrative perspective, communication methods, and communication channels:

With the help of civilian topics, TV news can firmly attract the attention of the audience. In today's era, it is the era of mass communication. All kinds of media are full of people's lives. What can really attract people's attention is often related to their own lives. Correspondingly, people have more to face the news. Initiative - The quality of news content is often judged by the public. Therefore, TV news content should now "go down and go into life" and conduct in-depth interviews, materials and editing through a series of topics closely related to civilian life, helping people "see" and trigger them to "think". "This is what truly reflects the consciousness of the people." TV news not only reflects "national events," but also reflects the warmth and warmth of the people. For example, local TV stations can carry out corresponding news topics according to local characteristics, and provide a comprehensive display of the development of local basic people's livelihood through continuous and in-depth reports, so that people can interview and record through journalists. Aspects that you cannot see, enhance your confidence in the cause, and be more active in participating and cooperating. So that TV news really plays the role of "send the love" and "send the situation".

Choose a civilian perspective so that TV news can actually smash the audience's mind. TV news rich in civilian consciousness can naturally not be separated from the "civilian" to look at the problem. Therefore, not only should the topic of civilians be emphasized in the selection of TV news, but also the sense of civilians should be reflected in the means of handling. This mainly includes two aspects: First, the language of TV news should be "popularized", that is, the news language should be concise and bright, and it is easy for the audience to accept information, because TV news is a kind of linear communication, and the audience is able to obtain information by means of instantness. While broadcasting, listening, and not thinking deeply, if the news language is relatively unfamiliar or long complex sentences, it is often difficult for viewers to quickly accept and understand the content. Even if the overall design of the news program is novel, it is difficult to resonate with the audience. On the contrary, the "popular" language, which is popular and popular, is more acceptable. Of course, the civilian language of television news does not mean speaking in tongues. In addition to special livelihood programs and dialect programs, standard Mandarin is still applied. Second, the handling of TV news topics must be "popularized." When TV stations or journalists face news topics, they must "give" news reports on the basis of a deep understanding of the people's mentality. Expressing opinions, we should actively support the viewpoint through specific materials, and let the audience experience and think through the process and details of the practice that the people care about. Such news can really touch the hearts of the audience.

The new form creates the credibility of television news. As a traditional media, TV news has an unshakable credibility, but with the development of the times, the credibility of TV news is constantly being challenged. How to occupy a place in the competition with new media requires TV journalists under the guidance of civilian consciousness. Actively reform and innovate. Compared with traditional media, the new media has the outstanding advantage of being more "intimate", able to grasp the timeliness and better interact and communicate with the audience, thus giving the audience a sense of intimacy and belonging. Therefore, in the process of TV news communication, we must embody the consciousness of the people, that is, we must actively absorb, draw on and utilize the advantages of the new media, so that the new media becomes an indispensable and indispensable part of its own, for example, actively developing advanced Mobile client software, using the TV station's Weibo, WeChat public number to reprint, publish TV news, or use the platform to achieve the "re-shaping" of TV news, thus forming closer contact and interaction with the audience, while at the same time grasping its own rich In the advantages of credibility, in each terminal, platform, "active voice", this advantage will be expanded.

Expand the influence of TV news through multiple channels. Because the consciousness of the 
civilians requires maximizing the psychological needs of the people, and it is necessary to obtain the favor of the audience in the context of the integration and competition of various media, it is necessary to strive for excellence in television news production. This includes about three aspects. One is to use modern technology to innovate the details of the editing and editing of TV news programs. Under the premise of exquisite form, the speed of the production of news programs can be greatly enhanced, which not only makes the news content richer. And it can greatly improve the timeliness; the second is to make more use of advanced technology and equipment in the editing process, such as real-time recording of public transportation conditions through digital video recording equipment, timely summary and release, and more effective use of intelligence in the process of communication Terminal devices such as mobile phones and tablet computers increase the coverage and utilization of mobile TV. The biggest advantage of new technology is to improve the efficiency of journalism. Let journalists and TV stations get first-hand news materials in a richer, more timely and three-dimensional way, with more time and energy on the finishing and refining of content. Therefore, if we want the civilian consciousness to be better applied and infiltrated in the news work, we must actively expand the channels of communication of TV news, and use new media and new technologies to make TV news between the two fulcrums of the quality of form and content. Get a balance, let TV news more accurately and effectively reflect the social situation and reflect the public's voice.

\section{Conclusion}

In the era of media media, the "civilian consciousness" in TV news work has a new meaning and standard. The civilians, that is, the audience's influence on TV news, is getting bigger and bigger, which determines whether TV news can occupy a place in the fierce competition. . Therefore, it is imperative to integrate the civilian consciousness into the TV news work. Incorporating the consciousness of civilians into TV news work requires TV journalists to seriously examine their own problems, and try to actively innovate and implement the awareness of civilians from the aspects of TV news topic selection, narrative perspective, communication methods, and communication channels. Let the production and broadcast of TV news more deeply meet the needs of today's society and the people, show the voice of the people, and make full use of advanced technology and means to regain the rigor and value of TV news and further enhance the news of TV news.

\section{References}

[1] Li Yuncai. The Civilian Consciousness of TV News in the Information Age [J]. New Media Research, 2017, 3(4): 129-130.

[2] Li Zhichao. On the rise of civilian consciousness in journalism [J].Western Radio and Television, 2016(24): 51-51.

[3] Duan Jing. How TV News Reflects the Consciousness of Civilians [J]. Journalism Research Guide, 2016, 7(19): 172-172. 